\title{
Mona in the mirror
}

\section{Freud's ambivalence to Leonardo's cathexis revisited}

\section{Digby QUESTED, Registrar, The Maudsley Hospital, Denmark Hill, London SE5 8AF}

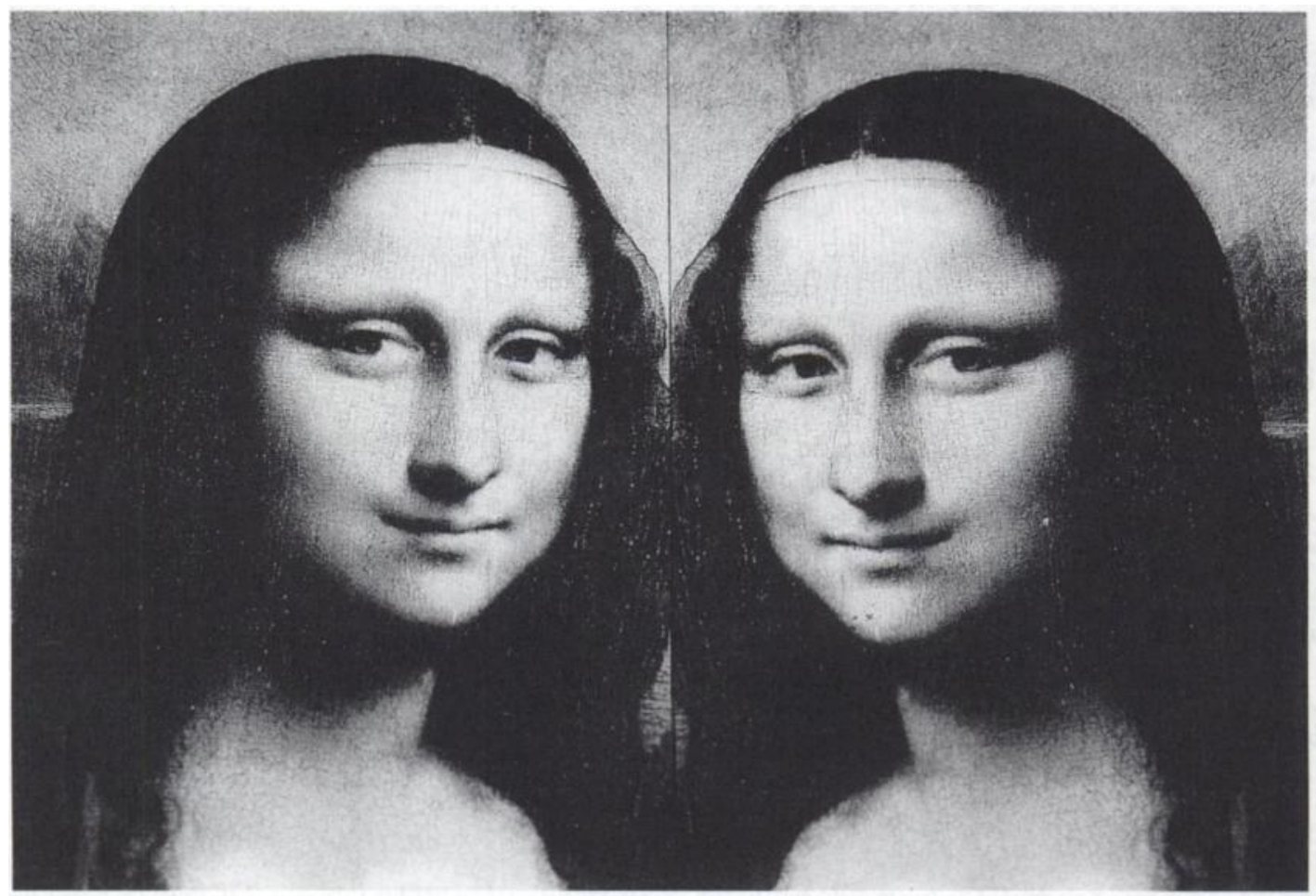

Fig. 1 Mirror image

FIG. 2 Original

\section{Background}

In 'Leonardo Da Vinci and a memory of his childhood', Freud (1910) provided an analysis of the artist's personality and sexuality, with a description of his capacity to sublimate his libido into creative works. He discussed the Mona Lisa's ability to command attention and induce differing emotions within the viewer. In his paper he described the distinct elements of her expression, "The contrast between reserve and seduction, and between the most devoted tenderness and a sensuality that is ruthlessly demanding-consuming men as if they were alien beings".
One can perceive that she is smiling and yet there is a sinister component. It is the origins of the word sinister which may provide an explanation for the effect.

Since Roger Sperry's (1977) work with patients whose corpora callosa were divided to ease intractable epilepsy, the existence of two selves, one logical, rational and analytical and the other visual, creative and gestalt has generally been accepted.

Further experiments have suggested that, due to the lateral splitting of the external world into our right and left visual fields, the hemispheres are obliged to recreate a whole face image from each hemi-face visualised on face to face contact (Levy, 1972). 
Although Vasari's biography of the great artists assures us jesters were used to amuse her, Mona Lisa smiles more with the left side of her face than the right which is normally true of 'decision' or 'forced' smiles and is usually a feature of males (Skinner, 1989). We know that Leonardo was left-handed and his hundreds of sketches and designs bear written annotations which testify to the fact that he also wrote in mirror-writing (Clark, 1988).

In light of the above, a mirror image was produced by inverting a photographic negative (Figs. 1 and 2). The mirror image was initially constructed to create two whole faces from each hemi-face visualised in the right and left visual fields. This was not successful in view of the angle of her head but viewing the mirror image as a whole was more enlightening. Her countenance appeared less enigmatic and more warm and appealing. This has been corroborated by numerous viewers.

The possibility that each hemi-face can give conflicting emotional information has been proposed, and the technique used experimentally in order to evaluate differences in hemispheric processing (David \& Cutting, 1990).

\section{Comments}

There are various explanations for this phenomenon. Leonardo, being left-handed and writing in mirror image, may have created the inversion unintentionally. However, the background of the painting suggests otherwise as it is completed with mountains which differ in form and height on each side of the midline, such that the scenery is not confluent. This would imply that he had designed the effect with the same precision as his perspective for the 'Last Supper'. The other possiblity is more complex but interesting in the light of possible psychodynamic interpretations. In 1986 a proposal was revived that the painting was actually a self-portrait (Schwartz, 1986). This was supported by the depiction of a computer-aided juxtaposition of the Mona Lisa with an acknowledged self-portrait of da Vinci. The facial features aligned exactly but the art critics were unimpressed. Freud, in his continuing analysis of her smile, suggested that it was subsequently found in his other works and was, in essence, an embodiment of himself.

Were da Vinci to have used a mirror for a selfportrait the necessary inversion would also have been obtained. Silver-backed mirrors were in use during the 15 th century and this would also account for the impression that her eyes meet the gaze of a viewer in any position in the room of the gallery.

Other evidence proposed to support the concept that the painting is actually a self-portrait has been the use of certain knots in the bodice of her dress which have a similar Italian word stem to his sur- name (vincire) as suggested by Professor M. Kemp. It has also been reported that $\mathrm{X}$-rays of the painting have revealed a bearded face beneath the existing surface. This may not be the use of a canvas for a second time but the superposition of a female face over an existing self-portrait.

Closer examination of his portrait and the mirror Mona reveals a similar three lobed blemish on the right aspect of the root of their noses.

The explanation may be a combination of the above possibilities if his motivation is conceptualised in psychodynamic terms. If one's unconscious choice of a love-object has a fundamentally narcissistic element and art is thought to involve the sublimation of libido, his choice of model and the embodiment of aspects of himself in its portrayal would be a form of cathexis (Freud, 1917).

According to legend Narcissus fell in love, not with himself, but with his mirror-image and Leonardo was almost certainly infatuated with the picture, keeping it with him until his death in Paris rather than returning it to a commissioner, if indeed there was one.

Leonardo's representation of himself as a female would concur with Freud's account of his probable homosexuality. Michelangelo, acknowledged as being homosexual in orientation, achieved his greatest cathexis in the 'David' in Florence. Leonardo's tutor, Andrea Del Verrochio, also constructed a David for which it is thought Leonardo himself may have posed. The caption to the picture of that statue in the anthology 'Great Artists' remarks on the enigmacity of 'his' half-smile and the younger features are not unlike the Mona Lisa.

\section{Conclusions and questions}

The explanation of the enigma of the Mona Lisa's smile, using the above framework of analysis, as a self-portrait in inversion, both according to laterality and gender, raises some questions concerning human interaction. In classical psycho-analysis does the analyst lose out on half the information relayed during face to face contact? Is bonding a measure of the concordance of emotional messages conveyed by both hemispheres and is it possible that discordant emotional messages conveyed during inter-hemispheric dysfunction, as is proposed in schizophrenia, may induce the 'praecox feeling' in an interviewer, or elicit high expressed emotion from family members in face to face contact?

As Leonardo Da Vinci was himself actually a mirror image in terms of neuroprocessing, rather than using mirror-writing to prevent others stealing his ideas, as some have suggested (Smetacek, 1992), did the inversion itself facilitate his creative genius and, if so, by what neurophysiological means? 


\section{Acknowledgement}

Mr Simon Brighton printed the inversion of the photograph of the Mona Lisa.

\section{References}

Clark, K. (1988) Leonardo da Vinci. London: Viking.

DAvid, A. S. \& Cutring, J. (1990) Affect, affective disorder and schizophrenia. A neuropsychological investigation of right hemisphere function. British Journal of Psychiatry, 156, 491-495.

Freud, S. (1917) The Development of the Libido and the Sexual Organisations. Introductory lectures on psychoanalysis. 362-382. London: Penguin Books.
(1910) Leonardo da Vinci and a memory of his childhood. The Complete Psychological Works of Sigmund Freud, Vol.11. London: The Hogarth Press.

LeVY, J. et al (1972) Perception of bilateral chimeric figures following hemisphere deconnection. Brain, 95, 61-78.

SCHWARTZ, L. (1986) January edition. Art and Antiques.

SKINNER, M. (1989) Face to face with asymmetries in facial expression. The Psychologist: Bulletin of the British Psychological Society, 10, 425-427.

SMETACEK, V. (1992) Mirror-script and left handedness. Nature, 355, 118-119.

SPERRY, R. W. (1977) Forebrain commisurotomy and conscious awareness. The Journal of Medicine and Philosophy, 2, 101-126.

\title{
The use of car telephones by psychiatrists
}

\author{
J. A. Henderson, Registrar; C. J. Simpson, Consultant Psychiatrist; and \\ J. D. MUMFord, Consultant Psychiatrist, Department of Mental Health, \\ Friarage Hospital, Northallerton, North Yorkshire DL6 1JG
}

As community services develop, medical staff are increasingly spending more time outside the hospital, despite the most severely ill patients still being in hospital. This may lead to junior medical staff and nurses feeling unsupported by the consultant. In addition, as more disturbed patients are kept out of hospital, the general practitioner and community health workers may require to contact the psychiatrist more often to talk about patients or to request urgent assessment. Therefore the importance of communication with consultants is increased both from the hospital and from the community while they are spending increasing amounts of time in their cars. In a discipline where communication is of paramount importance, a failure to meet this growing need would undermine the effectiveness of the service as a whole.

In Northallerton Health Authority this is a particular problem as it covers 1,000 square miles and is essentially rural. It includes the northern part of the Vale of York, Wensleydale, Swaledale and the western fringes of the North Yorkshire Moors (Simpson, 1989). It was therefore decided that the two consultant psychiatrists should each have a car telephone and that this be evaluated in terms of cost, avail- ability for discussion of patients with community and hospital staff, as well as contactability in an emergency.

At the time of the study, the two psychiatrists in the district had in-patient beds outside the district, one to the North and one to the South. However, they both did out-patient clinics and domiciliary work throughout their sectors and ran community day hospitals, a hospital hostel and dementia assessment wards within the district. They both spent many hours travelling in their cars and found that whenever they got to their destination they had a list of telephone calls to make.

\section{The study}

The study was divided into two parts; a study on cost and a study on quality.

In order to study the cost, all incoming calls to the car telephones were recorded over one year by one of the consultants. Each of these calls was rated as emergency or routine and the clinical consequences of being able to use the car telephone were noted. For each call an estimate was made of the time saved as a result of using the car telephone. In addition all 